\title{
Fifth-, sixth-, and seventh- grade students' use of non-classroom spaces during recess: The case of three private schools in Izmir, Turkey
}

\author{
Altuğ Kasalı, Fehmi Doğan* \\ Izmir Institute of Technology, Department of Architecture, 35430 Urla, Izmir, Turkey
}

\section{A R T I C L E I N F O}

\section{Article history:}

Available online 2 April 2010

\section{Keywords:}

Non-classroom spaces

Schoolyards

Recess

School architecture

\begin{abstract}
A B S T R A C T
This study investigates fifth, sixth, and seventh grade students' place preferences between indoor and outdoor non-classroom spaces during recess and their activity patterns in these spaces in three private elementary schools. The study explores whether differences in the variety and organization of the spaces of school facilities have an impact on the place preferences of students and whether students are aware of the reasons for their preferences. Students' place preferences and their activities were determined with field observations and a 30-item questionnaire with Yes/No and open-ended questions. A total of 173 students ( $n=51$ School $1 ; n=70$ School 2; and $n=52$ School 3) participated in the questionnaire. The Chi-Square test, a non-parametric statistical analysis test, was used to analyze the students' answers to the questionnaire. The results indicate that students prefer places which offer variety and which are large enough to avoid congestion and that, in general, students are aware of the spatial features of their environments and make choices accordingly. When students are given a choice of outdoors or indoors, they tend to choose according to which is more conducive to their activities. If both outdoor and indoor spaces are conducive, students tend to use both. If neither is conducive to their activities, students either alter their behavior patterns, for example, developing a preference for stationary activities or staying inside the classroom, or they convert available spaces to accommodate their activities. It is concluded that students are good sources of information in the design and planning of the environments they occupy.
\end{abstract}

(c) 2010 Elsevier Ltd. All rights reserved.

\section{Introduction}

There have been few attempts at conceiving the whole school building as a learning place (Dudek, 2000; Lackney, 1996; Pasalar, 2003) and students as primary and active occupants of the buildings. Since the early schoolhouse, the areas within school facilities where programmed learning activities occur have been often considered the primary or only places where learning takes place. Other areas within school facilities have been viewed as secondary, at best, or as having no function related to learning. What students do in these other places during recess has been either ignored or considered a waste of time, even detrimental to learning (Pellegrini, 2005). Blatchford (1998a) reports that there are few researchers who are interested in what children do during recess and what benefits recess may have on children's social and educational development. In contrast, a few researchers, such as Blatchford and Pellegrini (Blatchford, 1998a; Pellegrini, 1995, 2005), have underlined the

\footnotetext{
* Corresponding author. Tel.: +90 537 651367; fax: +90 2327507012.

E-mail addresses: altugkasali@iyte.edu.tr (A. Kasalı), fehmidogan@gmail.com (F. Doğan).
}

role of recess in education and have pioneered research in children's behavior patterns and their space preferences during recess.

In line with research on recess and the importance of school environments, the authors of this study assume that the entire school facility should be viewed as an active agent contributing to student learning and development and that students are in constant interaction with their environments, including in nonclassroom spaces. Consequently, we need to consider children's needs and preferences for use of recess time in the design of whole school facilities.

Our study investigates fifth, sixth, and seventh grade students' use of space and their preferences when they are outside the classroom in the case of three private schools in Izmir, Turkey. The three schools have significantly different spatial layouts, which makes it possible to discuss whether spatial properties have any impact on students' place preferences and activity patterns. The study explores whether differences in the spatial variety and the amount of available space per student have an impact on the place preferences of students during recess and whether their preferences are based on an understanding of the features of their environment. We think spatial variety is an important factor in the 
way students-with different needs and desires, from different age, and gender-relate to their environments in different ways following Gibson's theory of affordances about perception and its use in environmental psychology as exemplified in the work of Clark and Uzzell (2002).

The specific research questions of the study are:

1. Where do students prefer to spend their free time in these private elementary schools? Are the spaces preferred by students different from one school to another and are those differences related to the spatial features of the outdoor and indoor spaces?

2. What do students do in the places where they spend their free time? Are the activities preferred by students different because of the spatial features of their school facility?

3. Are students aware of the particular features of those places where they like to spend time during recess? What might be the reasons that students prefer to spend their time in specific locations?

We analyzed the findings to see whether the physical environment is a factor in children's play behavior and place preferences and whether their age and gender differences have an impact on their play patterns and place preferences. Among the different aspects of the physical environment, we looked specifically into the effect of the size and variety of spaces on the space preferences of students. We claim that the physical environment should provide first enough space for each student and second provide enough variety to meet the needs and desires of different students. This follows Pellegrini's suggestion (Pellegrini, 1995) that the physical and social aspects of the school environment are interactive and should not be dichotomized, and that the same environment could offer different affordances to different children. Furthermore, the study investigates how much and in what ways students are aware of the physical features of their environment, how students utilize these features, and what students do when the spaces available to them are not adequately designed knowing that children are adaptable to different environments, either by changing their behavior (Ozdemir \& Yilmaz, 2008) or by changing the environment (Catling, 2005; Kytta, Kaaja, \& Horelli, 2004) at the expense of the school or other existing authority (Thomson, 2005).

\subsection{Recess in schools}

Pellegrini and Blatchford (2002) state that recess is "crucial to academic achievement, peer relations, and more general school adjustment" (p. 62) and summarize empirical evidence regarding the benefits of recess and their respective theoretical explanations. Pellegrini (2005) proposes that recess is important primarily because of the principle of distributed activity and the deferred benefits of play behavior during recess. The principle of distributed activity suggests that for a sustained and effective level of interest, especially among younger children, it is necessary to distribute activities over periods of time separated by recess. Pellegrini also suggests that recess is important because the benefits acquired from play and game during recess, namely increased cardiovascular fitness and social competence, are more than the costs associated with play and game.

Another reason why recess appears to be important is that it is a time when children may undertake relatively less supervised and non-structured activities in one of the few places which is explicitly designated for their use. As Tovey (2007) suggests, in contemporary cities children have less and less free and safe access to places; and institutional settings, such as schools, become increasingly important as places designated for children. Studies have shown that students themselves value their school environment significantly. Burke (2005) found that students photographed the schools' open spaces the second-most in a study which asked primary school students to photograph their favorite places of play. Clark and Uzzell's study (2002), which investigated place preferences of adolescents in terms of their needs of privacy and social interaction, found that school settings can support both social interaction and retreat behavior, together with neighborhood and town centers. Furthermore, students think of the school grounds as their spaces (Titman, 1994) and they consider recess, which they spend generally in non-classroom spaces, their most favorite part of the school day (Evans, 1997).

\subsection{School environment and children}

The design of school grounds has importance for the social, intellectual, and cognitive development of children (DuránNarucki, 2008; Kumar, O’Malley, \& Johnston, 2008). In welldesigned school environments students often feel more valued (Catling, 2005) and feel more attached to their schools (Killeen, Evans, \& Danko, 2003; Kumar et al., 2008), which Spencer and Woolley (2000) claim is important in the formation of children's personal identity. The design of school grounds has been shown to impact students' level of physical activity (Collins \& Coleman, 2008; Ozdemir \& Yilmaz, 2008), and inadequate design of non-classroom spaces may have adverse effects on students either by way of problem behaviors (Kumar et al., 2008) or negative emotions (Thurber \& Malinowski, 1999). The conditions of the physical environment may adversely affect students' academic performance (Durán-Narucki, 2008; Tanner, 2000) and school attendance (Durán-Narucki, 2008), as well. Moreover, the schoolyard design may affect students' play patterns as suggested by Armitage (2005), in a study which shows that the schoolyards in England have been used for similar types of play over a period of many years.

Regardless of the importance of school spaces in children's lives and the lack of designated spaces for children's use in cities, children are generally ignored as information sources in the planning and design of cities and schools (Hart, 2002; Matthews \& Limb, 1999; Spencer \& Woolley, 2000). When it comes to the design of children's spaces, such as schools, the spaces are often shaped with mediocre design and building standards (Catling, 2005; Collins \& Coleman, 2008; Tanner, 2000). Even when concern is expressed for the quality of the design of school facilities, outdoor spaces and other non-classroom spaces are often the least-considered or are perceived only as places of secondary importance with no direct impact on the principal goals of schools (Catling, 2005). Tanner (2000) states that often the design of "green areas, natural quiet areas, and play areas" are not given enough attention. When there is some concern for the design of school grounds it is usually shaped according to adults' vision of what children ought to do during their recess hours (Collins \& Coleman, 2008; Dyment \& Bell, 2007). Moreover, teachers and educators do not have sufficient interest in the role of the physical environment on children's development (Catling, 2005).

Other researchers who have studied school buildings, on the other hand, have looked into the behavior patterns of children on the school grounds. Current research on the use of the schoolyard in general and other non-classroom spaces shows that diversity in the physical environment often fosters a variety of student activities (Dyment \& Bell, 2007; Lindholm, 1995), that students need solitary and private spaces as much as social spaces for retreat (Korpela, Kytta, \& Hartig, 2002), that spaces must be furnished with adequate facilities (Dyment \& Bell, 2007), that there should be sufficient space for both boys and girls (Thomson, 2005), and that natural elements and landscaping have a positive impact on students in general (Dyment \& Bell, 2007). 
1.3. Differences in play patterns according to physical environment, gender, and age

There is a substantial body of literature on the impact of physical environment on children's behaviors and on gender and age differences in the play patterns of children. Pellegrini (2005) states that children's play patterns vary according to playground type, gender, age, the time of the day, and the weather. Among these factors, this study only looked into spatial differences in the play environment, gender, and age. Pellegrini (1995, 2005), in reviewing the literature regarding playground type (such as traditional, contemporary, adventure, and creative) and its impact on children's play behavior, reports that children's play patterns vary according to the type of playground. G.T. Moore (1986), in a study which compares the activities in a schoolyard with three different zones-asphalt, main yard elements zone, and natural resources area-reports that all three areas were used equally, though students view the natural resources area as their favorite place. Moore's study shows that boys who prefer ball games favor the asphalt zone, while girls who prefer social interaction used the natural resources area. Extensive studies on gender differences in play behavior found that boys, more than girls, are physically active and prefer to be outdoors (Pellegrini, 2005). Blatchford (1998a) reports that at age 11 , boys more than girls, look forward to going out during recess, and that girls often have more concerns about being outdoors. Some have claimed that the gender difference continues during adolescence as well (Garton \& Pratt, 1987), although, the intensity of the physical activity of boys decreases with age (Blatchford, 1998a; Pellegrini, 1992); while others found no gender differences among seventh grade students (Pellegrini, 1995); and others report that secondary level students prefer sedentary activities more (Blatchford, 1998a). Lewis and Phillipsen (1998), in a comparison of first and second graders with fifth and sixth graders, found that boys use hard surface play areas more often, girls more often use treed areas, and older children use both play areas. When we look at what boys and girls do during recess, boys tend to be involved in ball games more often, and girls tend to be involved in more sedentary social activities (R.C. Moore, 1986; Pellegrini, 2005). In a study which looked at differences among boys aged 8-16, Malinowski and Thurber (1996) found that as boys grow up they prefer places because of their cognitive and aesthetic values, while younger boys prefer places for a particular land use. Studies have shown repeatedly that for more physical activity during recess children prefer ball games, games, running and chasing, and for less physical activity they prefer walking around, sitting and talking (Blatchford, 1998a; Heusser, Adelson, \& Ross, 1986; R.C. Moore, 1986; Pinciotti \& Weinstein, 1986). Tovey (2007) claims that children often associate indoors with adult supervision and that they believe themselves to be freer outdoors. Tovey claims that is why regardless of gender differences, children would prefer to be outdoors during recess. Groning (1986), however, reports that when there are no adequate outdoor amenities, neither boys nor girls go outdoors but stay inside.

\section{Methodology}

The cases of this research were selected among private elementary and middle schools in Izmir, based on their educational programs and on their characteristics of indoor and outdoor nonclassroom spaces. All schools in Turkey, private and public, share the same core curriculum set by the ministry of education. Differences in pedagogy reflect itself in the school management, extra courses, and activities offered outside of the core curriculum. The schools selected for this study have similar pedagogical objectives. As specified in their educational programs, all three schools have a student-centered active learning educational program with an objective of surpassing the traditional methods of education. None of the three schools had implicit or explicit rules of non-classroom space use during recess for the students within the age groups studied. All three schools require substantial and relatively similar amounts of yearly tuition, thus, almost all of the students included in this study come from middle-high and high income families. The socio-economic status of the students, the organizational structures of the schools, and the curriculum and teaching resources in the schools are similar to each other. We have not, however, documented this in our study. Earlier research comparing students attending public schools and private schools in Turkey has shown that the vast majority of the private school students' parents have at least a college degree, indicating that the private school students come from similar and higher socio-economic status (Tuncer, Ertepinar, Tekkaya, \& Sungur, 2005).

\subsection{Research instruments}

This study used two evaluation techniques: (1) questionnaires and (2) stationary and non-stationary field observations. Students from all grades were included in the field observation, while the questionnaire was conducted only with students from fifth, sixth, and seventh grades. The questionnaires included Yes/No questions related to students' indoor and outdoor space use and indoor and outdoor space evaluation. The questionnaire, administered under the supervision of one of the authors together with the teacher responsible for each classroom, also included open-ended questions aimed to determine students' favorite places in the school building and school garden.

The questionnaire was conducted with 173 students in total ( $n=51$ School 1; $n=70$ School 2; and $n=52$ School 3) (Table 1). Of 173 students, there were 87 boys, 85 girls, and 1 student who did not answer the gender question. There were 64 fifth grade students (age 10), 55 sixth grade students (age 11), and 54 seventh grade students (age 12). Which students will answer the questionnaire was determined with the school administration and the class teachers. Classes, which had available time, participated in the questionnaire; therefore, there are differences in the number of participants in terms of gender and grade levels. In School 1, all students participated in the questionnaire; in School 2, one third of the students; and in School 3, half of the students.

The results of the questionnaire data will be discussed in terms of significant differences among schools. When it is relevant, statistical results according to gender and grade will also be provided. A probe statistical analysis is conducted on students' answers to the questionnaire. The Chi-Square test, a non-parametric statistical analysis test, is used to investigate students' answers to the questionnaire. The answers to the questions are tested separately, according to the relative differences of the expected and observed sample. The $p$-value is used to show the significance of the difference among the case studies. $p$-Values smaller than $p<0.05$ show a significant difference among schools.

Table 1

Number of students, tallied according to grade, gender, and individual schools. Percentages show the distributions according to gender and age within each school.

\begin{tabular}{llll}
\hline Total number of & School 1 & School 2 & School 3 \\
\hline Students & 51 & 70 & 52 \\
Boys & $28(55 \%)$ & $27(39 \%)$ & $32(62 \%)$ \\
Girls & $23(45 \%)$ & $42(60 \%)$ & $20(38 \%)$ \\
5th grade & $14(27 \%)$ & $14(20 \%)$ & $23(44 \%)$ \\
6th grade & $32(63 \%)$ & $22(31 \%)$ & $16(31 \%)$ \\
7th grade & $18(35 \%)$ & $19(27 \%)$ & $15(29 \%)$ \\
\hline
\end{tabular}


$p$-Value $<0.01$ indicates that the mean difference between compared pairs is highly significant. For statistical analysis according to gender and grade, we looked at the whole set of subjects together, regardless school, which means that we did not look at gender and grade differences within schools. This is because the sample size for each school did not provide adequate number of observed instances for each category.

Field observations were conducted during four-day visits to each school, one of which was intentionally made on a rainy day. Regarding the local weather conditions, Izmir has a mild climate with a relatively rainy winter season, which suggests that open spaces could be used almost all year long except the rainy winter months. The observations were made during the Spring semester. The mean temperatures for the months of March, April, May, and June are $11.7,15.9,20.8$, and $25.7^{\circ} \mathrm{C}$, respectively, and the average number of rainy days for March, April, May, and June are 8.3, 8.4, 5.0 , and 2.2 respectively. ${ }^{1}$

During field observations, both spatial quality and space occupancy were observed and recorded. In terms of spatial quality, both indoor and outdoor spaces in each school were assessed according to the availability of different amenities, the variety of spaces they contain, and the level of accessibility to and between sub-spaces. The space assessment forms, in four parts, were completed mostly during class hours. Educational facilities assessment forms developed by Sanoff (2000b) and Lackney (1999) were used to prepare the space assessment forms and a checklist was developed for the assessment items. The following items were separately recorded in the space assessment form: (1) accessibility, (2) intelligibility of the space, (3) spatial demarcations, (4) circulation, (5) physical features, (6) furniture and field notes.

In terms of space occupancy, places students preferred during breaks and the number of students spending time at these places were recorded in the observation forms through stationary and non-stationary observations. We used place-centered behavioral mapping during observations. Stationary observations were conducted in the outdoor spaces where there was a wider field of vision; while for indoor spaces, which did not provide good visibility, non-stationary observations were conducted. The stationary observations at outdoors were recorded once in every 10-min break that students have throughout the day. The activities, the nature of activities (whether they are performed in groups or alone), number of participants to the observed activities, and the gender of participants were recorded together with where the activity took place. With similar interval and recording modules, the nonstationary observations were conducted through the non-classroom indoor spaces of school facilities during breaks. Prior to the final study, we conducted a pilot case study in a public elementary school, which helped fine-tune the observation recording method.

\subsection{Description of case study schools}

The cases have difference in terms of spatial variety and the amount of space available per student. In the first school (School 1) the outdoors provides a rich and large schoolyard while the indoors lacks in spatial variety. In the second school (School 2) the indoors provides a rich environment while the schoolyard lacks in variety and is smaller than in the other two schools. In the third school (School 3) the indoor spaces provide a rich environment and the schoolyard is large, however, provides relatively less variety. It is predicted that students from each school will more likely use those places which provide sufficient space per student and with

\footnotetext{
${ }^{1}$ Retrieved from Turkish State Meteorological Service, http://www.dmi.gov.tr/ veridegerlendirme/il-ve-ilceler-istatistik.aspx?m=IZMIR accessed May 10, 2009.
}

a variety of sub-spaces allowing students to engage in different activities.

A comparison of three schools in terms of their spatial and physical features is given in Table 2 . In summary, the school facilities differ from each other in terms of open and enclosed space per student, percentage of hard surface and soft surface garden area, size of the school, number of floors, ease of accessibility to the outdoors, and available outdoor and indoor spaces (Table 2).

School 1 is included in the study because of its predominant outdoor spaces. The buildings of the school are organized around a garden, including a pond and a swimming pool. The school garden, which includes an olive grove, a tangerine grove, a pond, a swimming pool, an amphitheater, and various play niches for students, provides a great variety in contrast to the barren doubleloaded corridors of the school building. School 2 is selected because of the variety of indoor spaces it offers to its students. The ten-story buildings surrounding the school garden house classrooms, sports halls, indoor playgrounds, cafeterias, a library, and activity areas, and theme places such as an "English House". Halls and corridors in School 2, however, lack variety and lack furniture. School 3 was selected for its emphasis on both indoor and outdoor spaces. The school provides various non-classroom indoor spaces and a large, easily-accessible garden space. The standard architectural program for elementary schools was expanded by the addition of a sports hall, a swimming pool, a multimedia center, an auditorium of 800 seats, an art center including ceramic, sculpture, and CAD-CAM workshops. All of these spaces for social activities are located along a $125 \mathrm{~m}$ long $\times 6.20 \mathrm{~m}$ wide "alley". The building has several direct accesses to the garden which encourages students to spend their breaks outdoors. The non-classroom indoor spaces of School 3 get direct natural light through skylights.

\section{Results}

The findings are summarized under two headings. Under the first heading, students' space preferences and assessments are reported based on the data from field observations, open-ended questions, and multiple-choice questionnaires. The results indicate how many students in each school prefer to spend time indoors or outdoors, how much spatial variety students report in their answers, and how satisfied the students are with their environments. Under the second heading, students' activities are reported based on results from open-ended questions and field observations. The data shows what kind of activities students are involved in, how prevalent these activities are in each school, and where students are engaged in these activities.

\subsection{Students' space preferences and assessments}

The field observation results indicate that students in School 1 were observed overwhelmingly outdoors, in $97.7 \%$ of all observations (Fig. 1). In School 2, students were mostly observed spending time indoors with $61.8 \%$ indoors, compared to $38.2 \%$ outdoors. Finally, in School 3 almost equal number of students were observed indoors and outdoors, with $48.7 \%$ indoors and $51.3 \%$ outdoors.

In the open-ended questions of the questionnaire, students were asked to describe their favorite places in the schoolyard and school buildings. In total, students made 529 references to particular spaces on the school premises ( $n=145$ School $1 ; n=277$ School 2; $n=107$ School 3) (Fig. 2). In School 1, students mentioned outdoor spaces more often $(58.6 \%$ of all mentioned spaces by students in School 1); in Schools 2 and 3, students mentioned indoor spaces more often (78\% and 57\%, respectively).

The students in School 1 mentioned various places in the school garden, such as the olive grove, the "place under the almond tree", 
Table 2

Space assessment summary of three case studies.

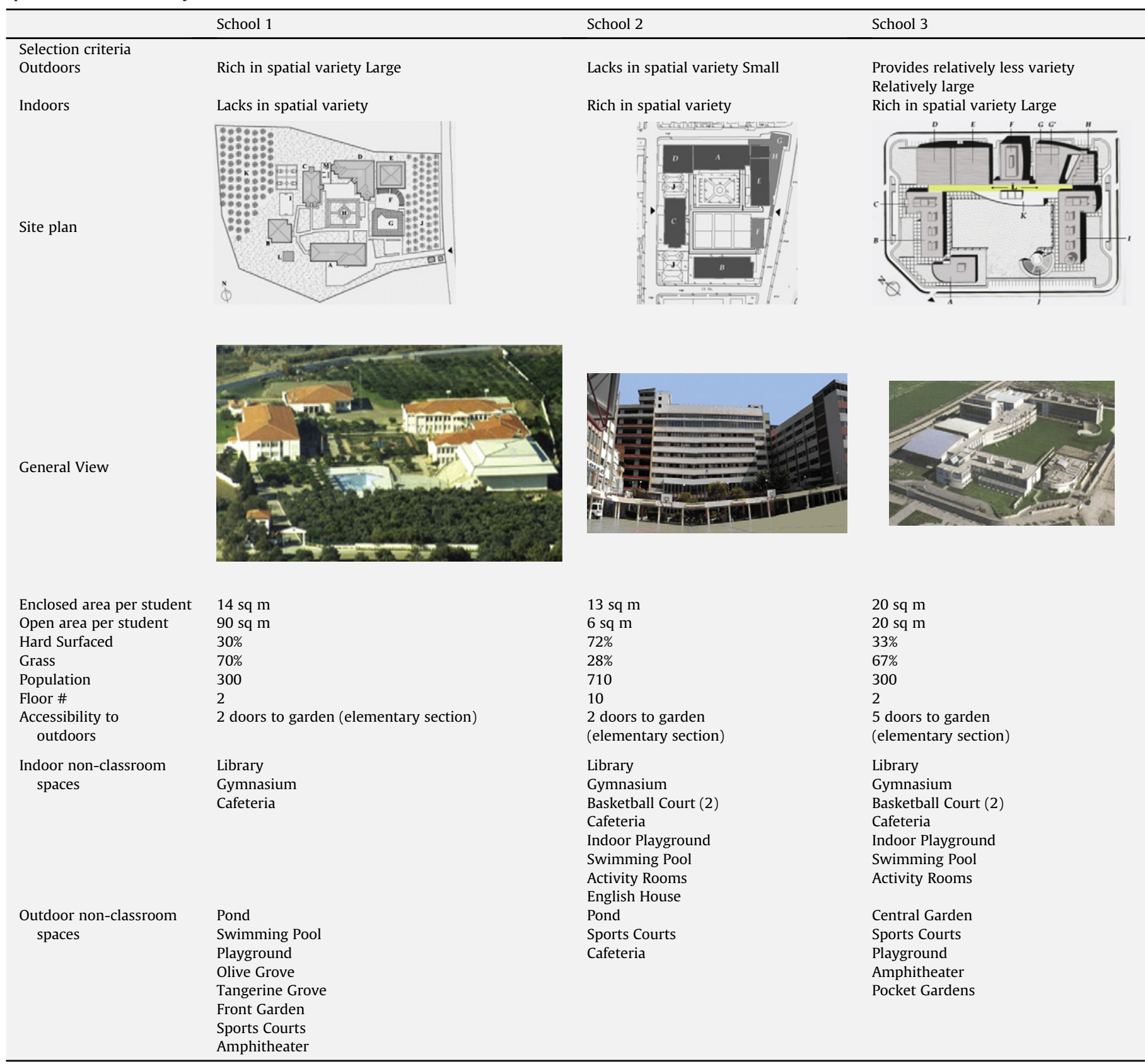

the pool, the benches under trees (Fig. 3), or the outdoor sports courts, as their favorite place, and fewer mentioned indoor spaces. The most common places mentioned by students in School 2 were mainly indoor spaces, such as fire stairs, corridors, or activity rooms together with the places in the garden, such as benches (Fig. 4), covered tiered seats. In School 3, places in the garden were the most favorite places mentioned by students (Fig. 5).

When indoor places mentioned by the students are categorized into three groups under the headings of non-classroom indoor spaces, classrooms and restrooms, and cafeteria (Fig. 6), we see that students in School 1 were least likely to mention a non-classroom indoor space (38.3\%), while students in School 3 mentioned many more non-classroom indoor spaces in their answers (80.3\%).

Statistical analysis of the multiple-choice questions shows a similar pattern in answers from the students of the three schools.
The results indicate differences according to gender and grade as well (Table 3).

When students' responses from three schools were compared, we found that there were significant differences in where students preferred to spend their time and what they thought about their school's facilities. When asked whether they would like to spend their recess time in the classroom $\left(\mathrm{Q} 2, \chi^{2}=32.782, p<0.001\right)$, in the school building $\left(\mathrm{Q} 4, \chi^{2}=66.995, p<0.001\right)$, or in the school$\operatorname{yard}\left(\mathrm{Q} 3, \chi^{2}=61.405, p<0.001\right)$, students' responses showed high significant differences among schools. In School 2, the percentage of those who stated that they stay inside the classroom during recess is overwhelmingly higher than the other two schools. Similarly, in School 2, the percentage of those who stated that they stay inside the school building is again higher than for the other two schools. In contrast, students in School 1 overwhelmingly 


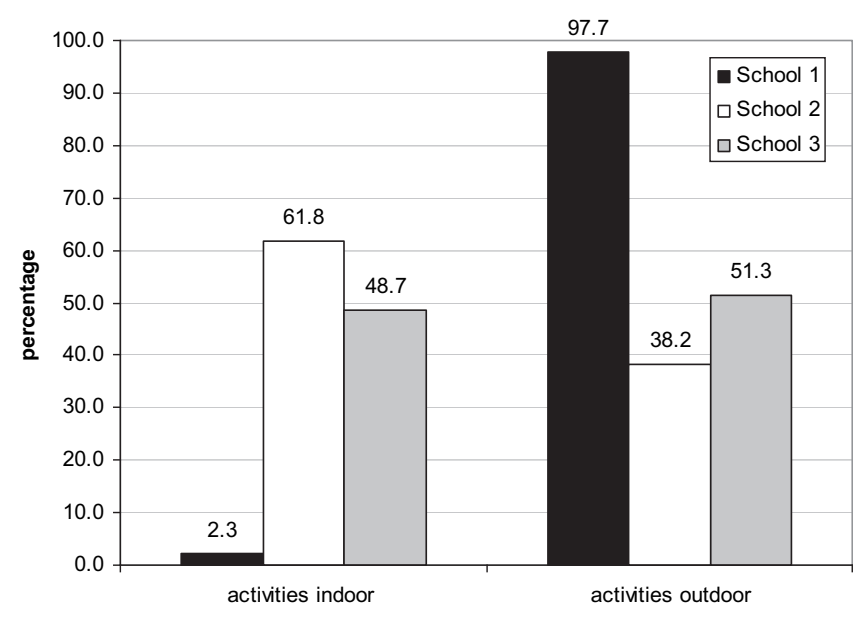

Fig. 1. Activity locations according to recorded observations.

stated that they go out to the garden during the recess. Students in School 3 stated that they equally often go out to the garden and stay inside the school building.

\subsubsection{Space preferences according to gender}

When the results are tabulated according to gender, we found high significant difference between girls and boys in terms of going out to the schoolyard during the recess $\left(\mathrm{Q} 3, \chi^{2}=11.0234\right.$, $p<0.001$ ). $67 \%$ of all boys from the three schools stated that they go out to the schoolyard during the recess, compared to $42 \%$ of girls. The percentages and differences between percentages for boys and girls in each school, however, vary from school to school. In School 1, high numbers of both girls and boys, $91 \%$ and $96 \%$ respectively, go out during the recess compared to School 2, where lower numbers of both girls and boys go out, $17 \%$ and $26 \%$, respectively. In School 3 , girls and boys both go outside less than they do in School 1 but more than in School 2.

\subsubsection{Space preferences according to grade levels}

When the results are tabulated according to grade level only, we found significant, but not high, difference between fifth, sixth, and

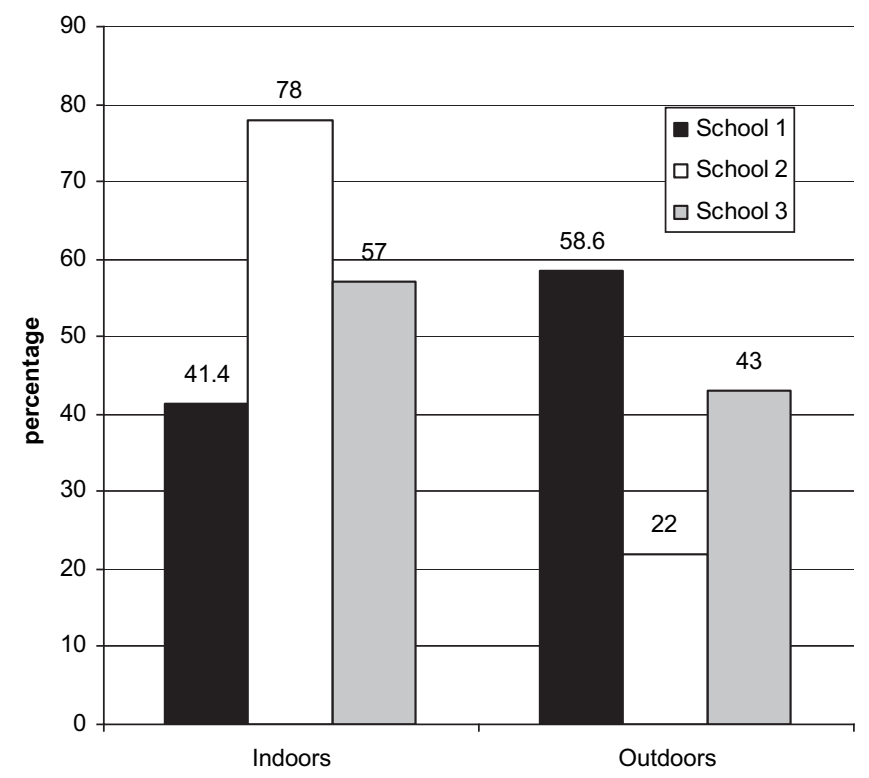

Fig. 2. Children's favorite places according to the questionnaire, classified into two groups.

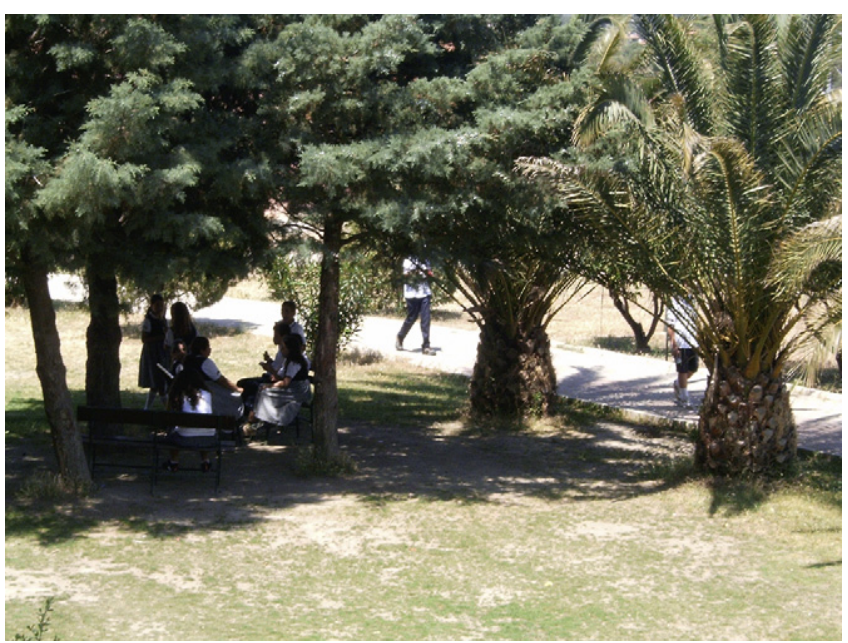

Fig. 3. Girl students in School 1 talking under the trees.

seventh grade students in terms of staying inside the classroom during the recess $\left(\mathrm{Q} 2, \chi^{2}=4.385, p<0.005\right)$. More fifth grade students (30\%) stated that they stay inside compared to sixth (16\%) and seventh (17\%) grade students. When the results are analyzed according to both grade level and adequacy of the size of the schoolyard, we see that in Schools 1 and 3, where the schoolyard is adequately-sized, almost all sixth grade (100\% in both Schools 1 and 3 ) and seventh grade (96\% in School 1 and 100\% in School 3) students stated that they do not stay inside the classroom compared to fifth grade students (29\% in School 1 and 17\% in School 3 ). In School 2, where the schoolyard is congested and lacks variety of space, there seems to be no difference among grades. In this school, almost equal percentages of students from each grade stated that they stay inside the classroom during recess $(44,45$, and $44 \%$ for fifth, sixth, and seventh grades, respectively).

\subsubsection{Students' space assessments}

The results of the responses to space evaluation questions show significant differences among schools, among grades, and between genders in terms of students' evaluations of the indoor and outdoor spaces of their school facilities as well. When schools are compared, the schools differ from each other significantly in terms of the congestion in outdoor spaces (Q29, $\left.\chi^{2}=11.681, p<0.005\right)$, places inside the school that students can sit and talk (Q27, $\chi^{2}=20.784$,

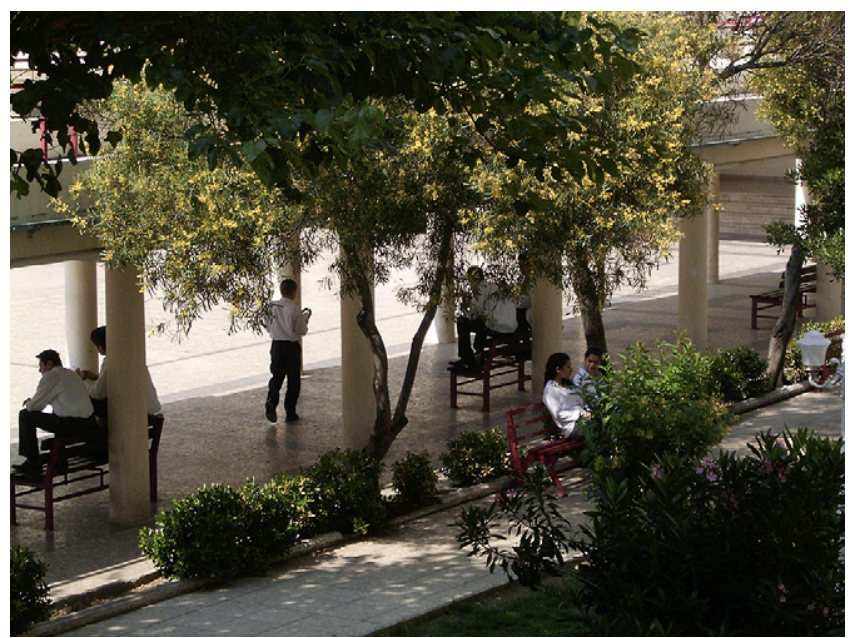

Fig. 4. Students in School 2 sitting on benches under the bridge. 


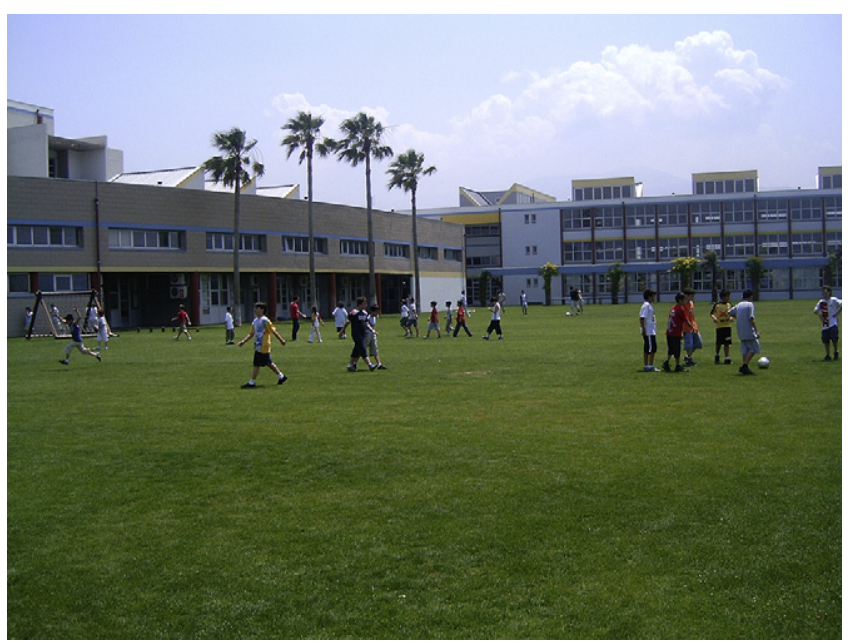

Fig. 5. Students in School 3 playing in the large schoolyard.

$p<0.001$ ) or can play games (Q30, $\left.\chi^{2}=25.905, p<0.001\right)$, and interior places that students like very much (Q17, $\chi^{2}=52.911$, $p<0.001$ ). In School 2, which has the lowest square garden area per student and the most crowded school, $41 \%$ of the students think that their schoolyard is congested. The percentages for the same question are lower in School 1 (14\%) and School 3 (29\%), both of which have higher square garden area per student. In terms of the students' evaluation of interior spaces, fewer students (27\%) in School 1, which has the least variety in the interior spaces among the three schools, have favorite places that are indoors compared to students in Schools 2 and 3 (83\% and 85\%, respectively). Similarly, in terms of places where students can sit and talk and places where they can play, fewer students in School 1 thought that there were such spaces available compared to Schools 2 and 3.

\subsubsection{Students' space assessments according to gender}

When space evaluation answers are analyzed according to gender, we found that there is significant difference between boys and girls in terms of the perceived sufficiency of a variety of places

\section{Students' favorite indoor places}

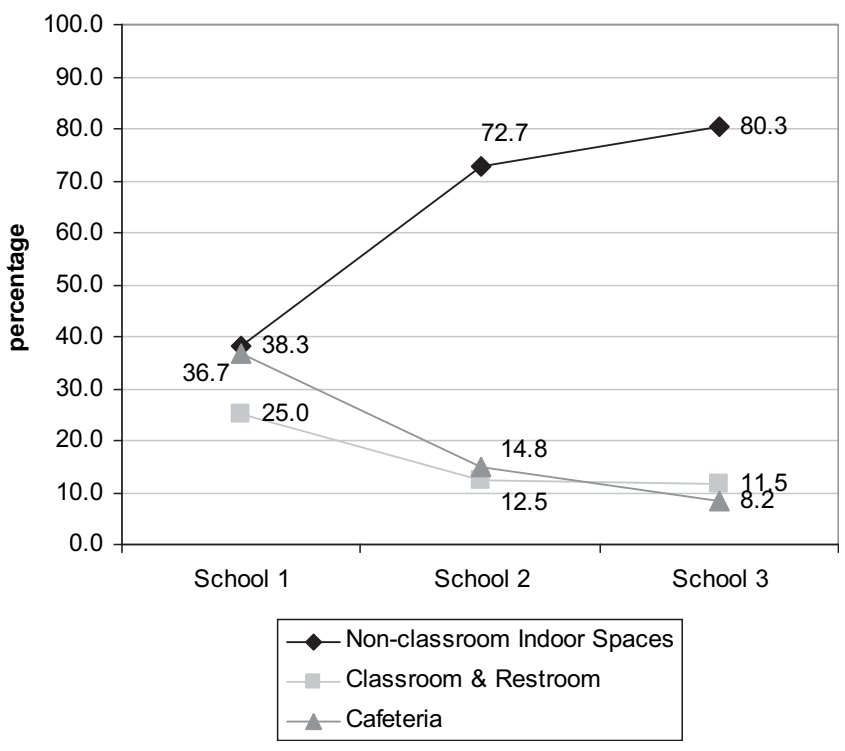

Fig. 6. Percentages of favorite indoor places in three schools. inside $\left(\mathrm{Q} 30, \chi^{2}=7.065, p<0.001\right)$ and outside $\left(\mathrm{Q} 28, \chi^{2}=6.879\right.$, $p<0.001)$. Significantly more boys think they have enough variety in interior spaces (68\%) and exterior spaces (87\%) where they can play, compared to girls (61\% and 69\%, respectively). In School 1, more girls think that there are a variety of outdoor places than boys, compared to girls in Schools 2 and 3. In interior spaces, we see a similar tendency among girls. In School 3, which offers the most enclosed square area per student and indoor variety, more girls (85\%) think they have a variety of indoor places in which they play compared to boys (68\%). In other schools where the variety offered and the size is less than School 3, boys are more likely to think that they have a variety of indoor places.

\subsubsection{Students' space assessments according to grade levels}

When results are analyzed according to grade levels, we found that students from different grades have significant differences in their evaluations of indoor and outdoor spaces as well. There are significant differences among grade levels in which places inside the building they like $\left(\mathrm{Q} 17, \chi^{2}=6.474, p<0.001\right)$, in the perceived availability of a variety of spaces in which they can sit and talk (Q27, $\left.\chi^{2}=2.69, p<0.05\right)$ and in which they can play $\left(\mathrm{Q} 30, \chi^{2}=14.46\right.$, $p<0.001)$. Regarding outdoor spaces, there are significant differences in the outdoor places they like (Q16, $\left.\chi^{2}=4.015, p<0.05\right)$, in the perceived availability of a variety of outdoor places in which they can play $\left(\mathrm{Q} 28, \chi^{2}=3.544, p<0.01\right)$, and the perceived congestion of the outdoor spaces $\left(\mathrm{Q} 29, \chi^{2}=9.896, p<0.01\right)$.

Students' responses to Q17 show that fifth grade students (74\%) state that there are places they like inside the school building more than sixth and seventh grade students do (69\% and 52\%, respectively). As students' get older their level of satisfaction with the interior space of the school building decreases. This is observed in each school separately. Our results show a similar decrease in the level of satisfaction with the schoolyard (Q16). The percentage of students who are satisfied with their schoolyard decreases from $85 \%$ of fifth grade students to $76 \%$ of sixth grade students and $73 \%$ of seventh grade students. When the evaluations of students from each school are analyzed separately, however, the results do not show a similar tendency, except in School 1. When we look at the available outdoor spaces, more higher grade students (40\% for sixth and $32 \%$ for seventh grade) tend to think their schoolyard is congested compared to fifth grade students (15\%), and as they get older they think there is less and less available outdoor space where they can play games (85\% fifth grade, $56 \%$ sixth grade, $46 \%$ seventh grade).

When schools are compared to each other, the results show no statistically significant difference in terms of students' satisfaction with places in the garden ( $Q 16)$ and students' perception of the availability of indoor space (Q 25) and outdoor space (Q 26) where they can be alone, and students' perception of the availability of outdoor spaces where they can play a variety of games (Q 28).

\subsection{Students' activities}

In the open-ended questions students were also asked to describe their activities in their favorite places (Fig. 7). In School 1, students reported 140 activities in total, among which 'talking' (20\%), 'playing games' (16.4\%), 'eating something' (14.3\%), and playing ball games or sports (11.4\%) are the most common activities. In School 2, students reported 171 activities in total, among which 'talking' (22.2\%), 'playing games' (26.9\%), and playing ball games or sports (13.5\%) are the most frequent activities. In School 3, students reported 95 activities in total, among which playing ball games or sports (35.8\%), talking (25.3\%), and playing games $(14.7 \%)$ are the most common activities at their favorite places.

The results from field observations support the results from students' answers to the open-ended questions. During visits to the 


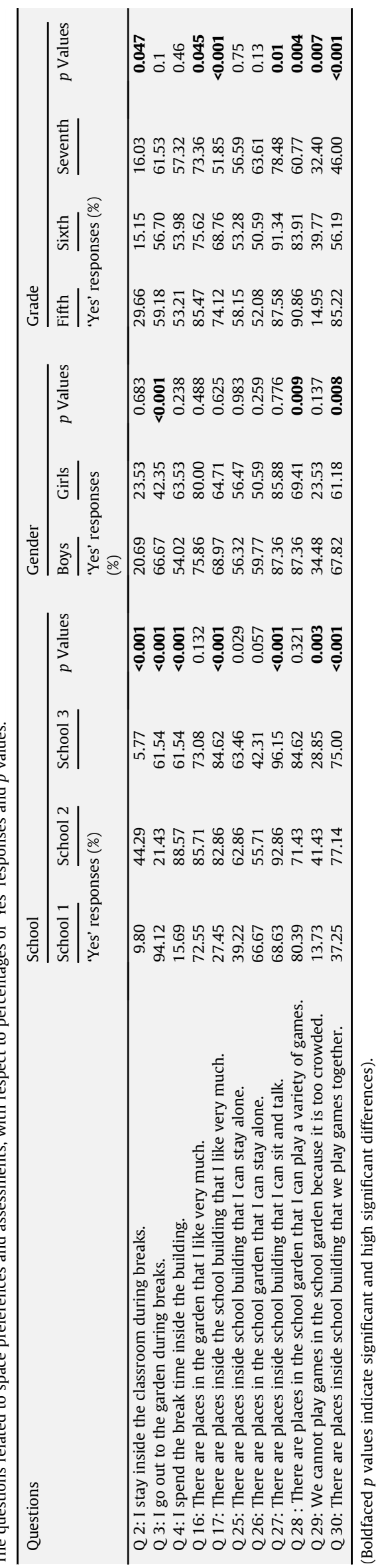

three schools, in total 352 indoor and outdoor activity observations were recorded ( $n=129$ School $1 ; n=110$ School $2 ; n=113$ School 3 ). When results from the three schools are tallied according to activities, 'playing games' (15\% in School 1, 15.5\% in School 2, and $20.2 \%$ in School 3), 'playing ball games' (23.9\% in School 1, 23.6\% in School 2, and 19.4\% in School 3), 'wandering and talking' (31.9\% in School 1, 10.9\% in School 2, and 10.9\% in School 3), and 'talking' (20. $4 \%$ in School 1, 24.6\% in School 2, and 14.8\% in School 3) are the most frequently observed student activities (Fig. 8).

\subsubsection{Students' activities according to gender}

When student activities recorded through observations are analyzed according to gender differences, we find that the most frequent activity of girls in every school is 'wandering and talking' (60.5\% in School 1, 45.9\% in School 2, and 77.2\% in School 3). In boys, the activities are more varied and 'playing ball games' is the most frequent activity for boys in every school (39.8\% in School 1, 42.3\% in School 2, and 34.4\% in School 3). In open-ended questions, girls mention 'talking' as their most favorite activity (25.4\% in School 1, 24.5\% in School 2, and 31.25\% in School 3). Among boys, however, 'playing ball games' is the most mentioned activity only in School 3 (36.8\%). In the other two schools 'playing games' is mentioned by boys as the most frequent activity by boys (20\% in School 1 and $28.8 \%$ in School 2).

\subsubsection{Students' activities according to grade levels}

When students' answers to the open-ended questions are analyzed according to grades, we found that among seventh grade students 'talking' is most frequently mentioned in all three schools (27.5\% in School 1, 48\% in School 2, and 35.7\% in School 3). Among sixth grade students, in School 1 'playing games' is the most frequently mentioned ( $22.9 \%$ in School 1 ), in School 2 'talking' (26.8\%), and in School 3 'playing ball games' (35.7\%). Among fifth grade students 'playing ball games' is the most frequently mentioned activity in all three schools $(28.6 \%$ in School 1, 32.1\% in School 2, and 36.4\% in School 3).

\section{Research questions and discussion}

\subsection{Spatial features and students' space preferences}

Research Question 1: "Where do students prefer to spend their free time in these private elementary schools? Are the spaces preferred by students different from one school to another and are those differences related to the spatial features of the outdoor and indoor spaces?"

Results from open-ended questions, multiple-choice questions and field observations show that students' preferences between outdoor and indoor spaces change from one school to another, between boys and girls, and among different grade levels.

We found that there are high significant differences among students from different schools in terms of their space preferences. When asked whether they would stay inside the classroom, stay inside the school building, or go out to the schoolyard, the high majority of students in School 1 stated they would go out; in School 2 most students stated they would stay inside the building or stay in the classroom; and in School 3 equal percentages of students stated they would go out or stay inside the building (Fig. 9).

During field observations of students during recess, almost all students in School 1 were observed outside, while in School 2 mostly inside, and in School 3 almost equal numbers of students were observed inside and outside. Observation results indicate that the schoolyard of School 1 is heavily used by students when compared to the other two schools. The schoolyard of School 2 is insufficient in 


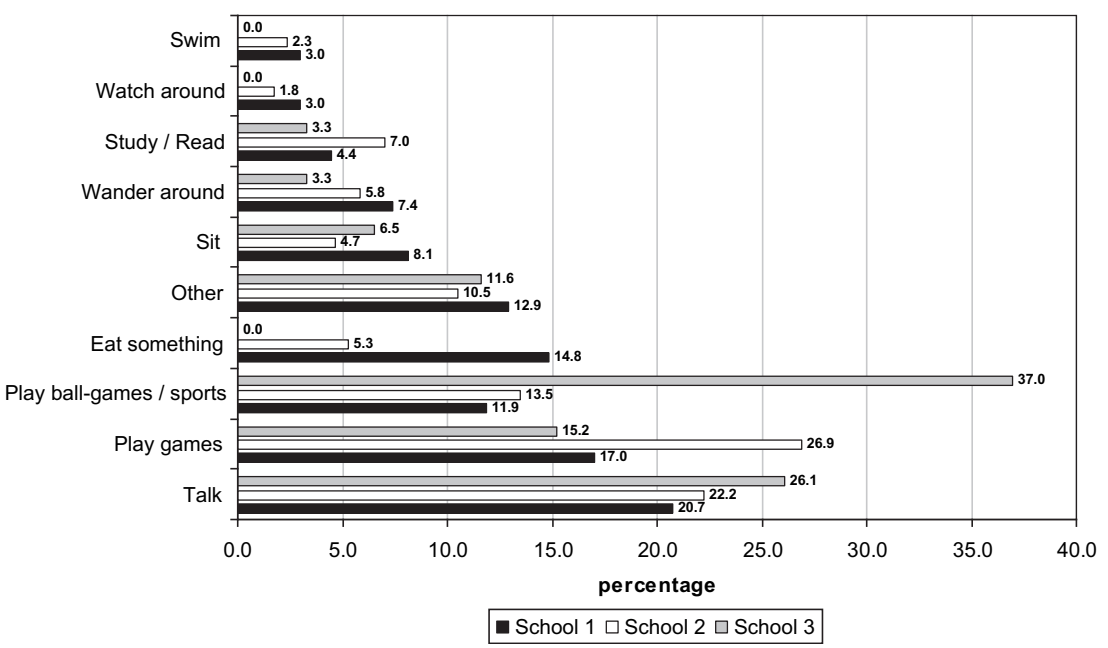

Fig. 7. Activities mentioned in open-ended questions.

terms of square area and the variety it offers, in addition to problems of access to the garden from interior spaces. In School 3, the garden is heavily used, even though it does not provide much variety when compared to School 1. Based on questionnaire responses and field observations, we conclude that students in School 1 prefer to go out during recess to the schoolyard, which is large and has variety in subspaces, compared to the interior spaces which do not provide variety. Students in School 2 do not prefer to go out to the schoolyard, which has the smallest area of the three cases and which does not provide variety. They, rather, stay either in the classroom or elsewhere inside the building. In School 3, students prefer interior and outdoor spaces equally.

Students' responses to those questions about their assessment of school facilities indicate that students in each school are aware of the spatial and physical features of their environments. This might suggest that students' preferences of where to spend their recess time are based on the spatial properties of their environment. In School 1, students mentioned more outdoor places, more outdoor favorite places, and were least likely to mention a non-classroom interior space. They were also least likely to have indoor places that they like very much and least likely to state that there are indoor places where they can play games and sit and talk. Conversely, they are also least likely to state that their schoolyard is too crowded. In School 2, students mentioned more indoor spaces and more indoor favorite spaces, and are more likely to think that their schoolyard is

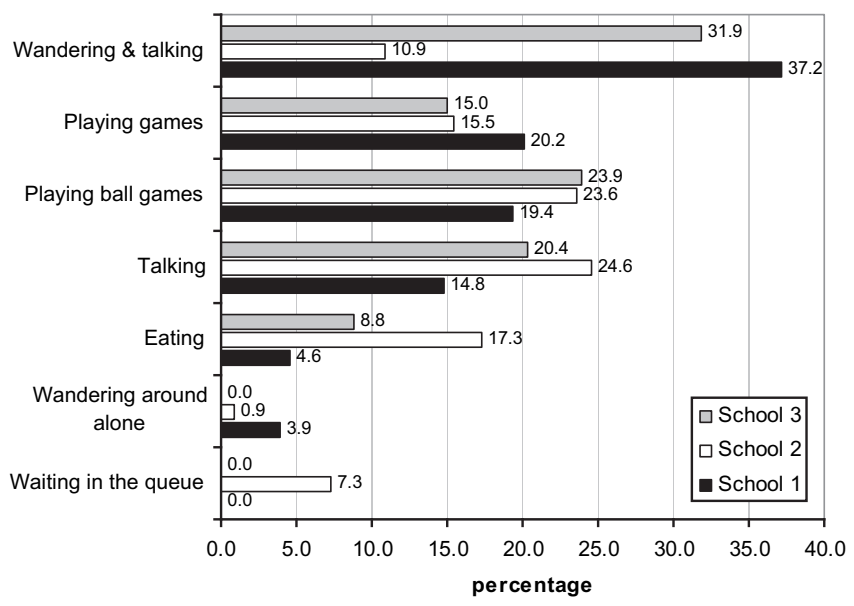

Fig. 8. Student activities according to recorded observations. crowded. In School 3, students referred to more indoor spaces, indoor non-classroom spaces, and more favorite outdoor places. Their responses show also that, compared to the students of the other two schools, they were more likely to have a favorable opinion of both their indoor and outdoor spaces.

The results indicate that students prefer those spaces that offer variety (e.g., the garden of School 1 and the interior spaces of School 2 and School 3), that are easily accessible (e.g., the garden of School 3 ), and that are large enough to avoid congestion (e.g., the garden of Schools 1 and 3). It seems that when the schoolyard is large enough, students feel freer and less supervised as well. A seventh grade, boy student from School 3 writes that "The schoolyard is my favorite place at school. We can freely play in the yard. This is the place where our teachers have the least intervention in what we do. Our schoolyard is really big." 2 When there are problems of access from indoors to outdoors and when there is congestion in the nonclassroom spaces indoors, students are more likely to stay in their classrooms during recess (e.g., the classrooms of School 2). A sixth grade, girl student from School 2 describes the congestion in their school as follows: "My classroom is one of my favorite places because I can stay where I am during recess with my friends and I can enjoy talking to them in the classroom. Also the schoolyard, because I can have fun there. The schoolyard is big and beautiful but most of the time it is very crowded".

\subsubsection{Gender differences in space preferences}

The analysis of the results according to gender illustrates that during recess girls in general stay inside the school building and boys in general go out, as the literature suggests (Blatchford, 1998a; Pellegrini, 2005). The results of this study indicate high difference between boys and girls in going out to the schoolyard. When we look at the data more in detail, we see, however, that preferences of both genders change according to the setting even though gender differences remain constant. When the interior space is not adequate, as in School 1, both boys and girls will overwhelmingly go outside. On the other hand, when the outdoor spaces are not adequate, as in School 2, even boys seem to not want to go outside during recess. In the case of School 3, where both indoors and outdoors provide adequate spaces, girls' and boys' preferences seem to follow the trends suggested in the literature. In School 1,

\footnotetext{
${ }^{2}$ The translations of students' responses to open-ended questions were done by the authors.
} 


\section{Students' space preferences during breaks}
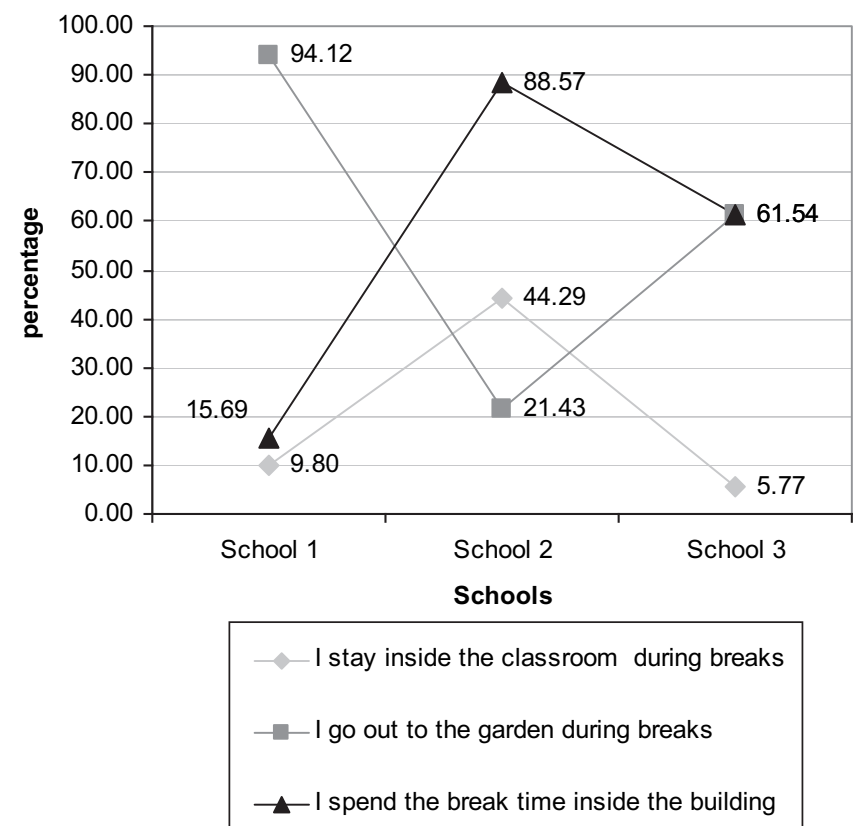

Fig. 9. Students' space preference according to the questionnaire.

almost equal percent of boys and girls (96\% and 91\%) stated that they prefer to go outside, which are the highest percentages among the three schools. In School 2, boys and girls both are less likely to go out $(26 \%$ and $17 \%)$; these are the lowest percentages among the three schools. School 3 has the highest percent difference between boys and girls in terms of going out ( $75 \%$ and $40 \%$ ), but this does not seem to be a problem for School 3 girls because they, more than the girls in other schools and more than boys in their own school, think there is enough variety in the indoor spaces. Boys in all of the three schools are generally more content with the availability of both varied indoor and outdoor spaces, with the exception of the girls in School 3, who think that there is sufficient variety in indoor spaces in their school. It tends to favor girl students more if outdoor space resources-the size and the variety offered-are adequate.

Our results suggest that among early adolescents there is a continued gender difference in the use of outdoor and indoor spaces (cf. Pellegrini, 2005). Girls tend to stay inside, unless the indoor spaces are inadequate, as in the case of School 1. Boys tend to go outside, unless the outdoor spaces are inadequate, as in School 2. Furthermore, we see sometimes a decline and sometimes an increase in gender preferences of indoor and outdoor spaces according to their respective spatial qualities, even though the gender differences remain constant. The environment, therefore, seems to have an important effect on the space preferences of both boys and girls (Pellegrini, 2005).

\subsubsection{Grade level differences in space preferences}

The analysis of results according to grade did not indicate any significant differences in staying inside the school building and going out during recess. It showed, however, significant difference in staying inside the classroom. Fifth grade students in all the three schools were more likely to state that they stay in the classroom, which could be explained by the fact that the younger students have less opportunity to use the amenities provided. In Schools 1 and 3, almost all sixth and seventh grade students stated that they go outside during recess. In School 2, almost an equal percentage of students from different grades stated that they stay in the classroom, which suggests that in this school the congestion in indoor and outdoor non-classroom spaces and the lack of sufficient outdoor space forces students of all levels to stay in their classrooms. Pellegrini (1995) found that in adolescence children become less physically active and prefer less to be outdoors. The argument that adolescent boys are getting to be less and less active, may not always suggest that they will be spending less time at outdoors. Blatchford (1998a), for example, found that both 11 and 16 year old boys preferred to go outside during recess.

In summary, our results indicate that the environmental differences in school facilities have an impact on students' preferences, regardless of their gender and grade differences.

\subsection{Spatial features and students' activity preferences}

Research Question 2: "What do students do in the places where they spend their free time? Are the activities preferred by students different because of the spatial features of their school facility?"

Almost all students from each school want to socialize during break hours according to students' responses to Q1. Students overwhelmingly stated that they do not want to stay alone during recess $(96.08 \%$ in School 1, 88.57\% in School 2, and 98.08\% in School 3 ). This result suggests that regardless of spatial differences in schools, the great majority of students want to interact with others during recess.

According to activity observation records, the dominant activities of students during recess are 'wandering and talking', 'playing games', and 'playing ball games', including basketball, football, volleyball and ping-pong. It may be concluded that students prefer to spend time together in groups talking to each other or playing games. The students' own reports of their activities support the results of the activity observation records. The three activities most frequently mentioned by students are 'talking', 'playing games', and 'playing ball games or sporting'. The prevalence of ball games and games (Blatchford, 1998b; Heusser et al., 1986; R.C. Moore, 1986), activities toward social interaction (R.C. Moore, 1986), and talking, wandering, and just sitting (Blatchford, 1998b) have been suggested in previous research as well. Our research indicates that this tendency holds true for fifth, sixth, and seventh grade students.

Students' activities during recess do not change from one school to another according to our field observations and students' answers. The prevalence of activities and where they occur, however, are different in three schools (Fig. 10), which may be explained by differences in the physical environment. The prevalence of 'wandering and talking' is higher in School 1 and in School 3 than in School 2 (5.5\%, both indoors and outdoors). The large garden of School 1 and the long alley of School 3 allow students to take long walks with their friends. In comparison, students in School 2 cannot easily take walks because of congestion both indoors and outdoors. In outdoor spaces in School 2, the most common activity is 'sitting and talking', because the garden is not large enough for the school population and does not offer a variety of spaces. The percentage of 'playing ball games' outside in School 2 is the lowest of the three schools as well. In addition, the stationary activities in indoor nonclassroom spaces in School 2 constitute a higher percentage of all activities in comparison to other two schools.

The results indicate that among students the preference for different activities changes according to the spatial characteristics of the schools. Whether students are involved in more stationary activities or in interactive dynamic activities seems to be influenced by the spatial features of the environment. It is likely that students who are not provided with adequate indoor and outdoor spaces will tend to stay inside their classrooms more and will tend to be more stationary, as in the case in School 2. 


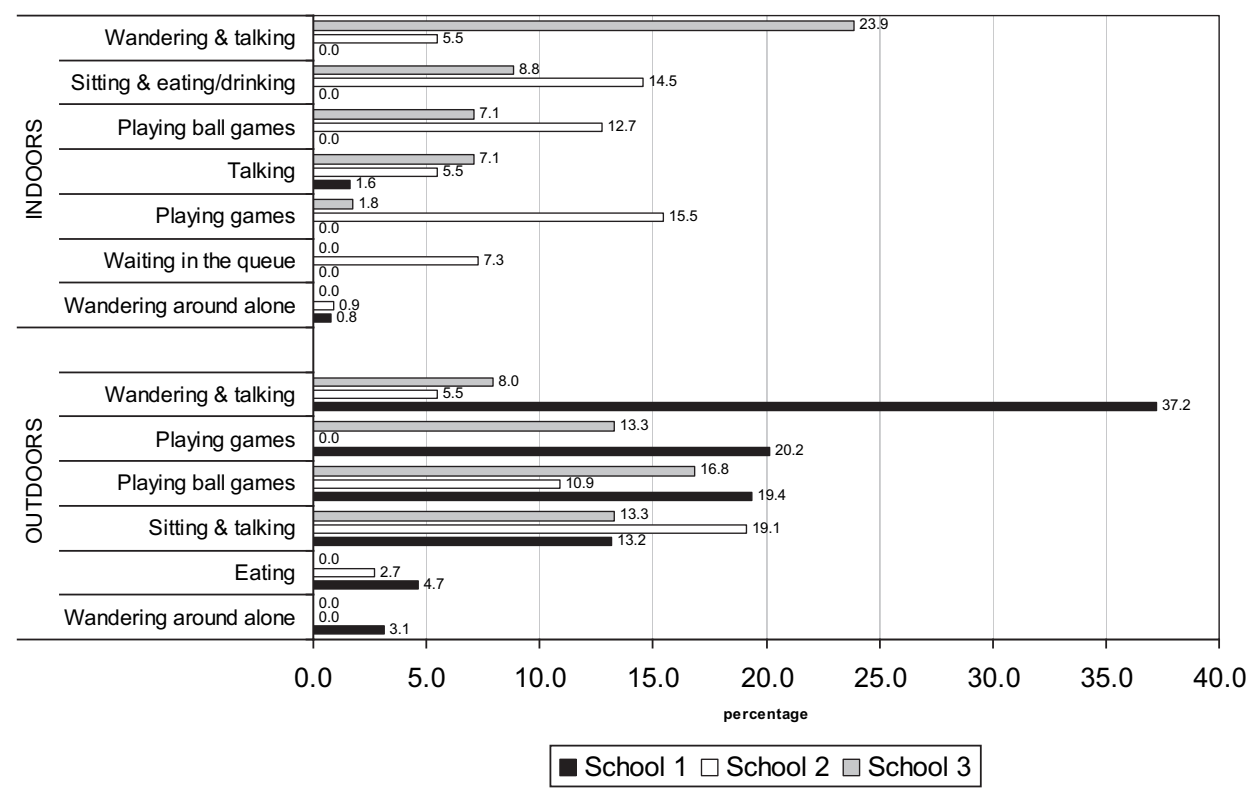

Fig. 10. Students' activities according to recorded observations.

\subsubsection{Students' activity preferences according to gender and grade} levels

When the results are analyzed according to gender and grade differences it appears that girls are involved in sedentary activities such as talking more than boys are (Pellegrini, 2005; Pellegrini, Kato, Blatchford, \& Baines, 2002), and boys are involved more in physical activities than girls (Pellegrini, 2005; Pellegrini \& Smith, 1998). A seventh grade, girl student from School 1 describes their talking behavior as follows: "We just sit around with our friends and talk about anything which comes to our mind. Not too much about classes. But mostly about teachers, other students, friends, our families, etc... We either gossip or we just do small talk. It feels good after the class hour. That is why we don't have rational topics and discussions." The results according to grade indicate that as children get older they favor sedentary activities more than intense physical activities, which is suggested in the literature as well (Pellegrini, 1995). The results indicate that there is a shift from 'playing ball games' to 'talking' as students move from fifth grade to seventh grade. In sixth grade we found that the results change from school to school, which could suggest that the sixth grade is a period of transition when preferences have not changed according to age yet. The results suggest a shift in students' perception of the availability of space as they get older as well. When we look at students' evaluations of available indoor spaces where they can sit and talk and where they can play games, the results indicate that as students get older they tend to think there is less and less space for sitting and talking and playing games.

\subsection{Spatial features and students' awareness}

Question 3: "Are students aware of the particular features of those places where they like to spend time during recess? What might be the reasons that students prefer to spend their time in specific locations?"

The results show that students from three schools are aware of features of their environments. Both girl and boy students spend their time in those places, indoor or outdoor, which offer enough space per student and which offer enough variety for different activities. Based on observation results, in School 1, students overwhelmingly preferred the school garden and very few of the students tend to stay indoors. In School 2, students are more likely to stay indoors. In School 3, students prefer equally indoors and outdoors.

We can assume that students are at least tacitly aware of their environments, based on where they are seen to prefer to spend their recess. When we analyze students' responses to open-ended questions and to Yes/No questions, we found that students actually know the spatial features of their environment and when asked they could report them. The results suggest that students' preferences of outdoor or indoor space is not due to chance or only tacit knowledge. Only one out of four students in School 1 stated that there are places they most like inside the building, compared to eight out of 10 students in Schools 2 and 3. This indicates that students in School 1 do not have a high opinion of the indoor spaces, which also describes why students in School 1 prefer to spend time outside in the garden and why they prefer cafeteria or classrooms as their favorite indoor places, rather than other nonclassroom spaces. Students' answers indicate that, in School 1, students do not have enough indoor places where they can play games or sit and talk compared to other schools. In terms of outdoor space use, response from School 2 students is revealing because the students report that their schoolyard is too crowded to be able to play games. The schoolyard of School 2 has the least amount of space per student, and students in this school are well aware of the deficiency.

The results indicate that students may be a reliable source of information during the design of the environments where they are going to spend their time. In line with our results, current thinking in the area of the sociology of children suggest that children are active agents in constructing their lives and their environments, as opposed to passive agents who need to be coached at every step (Corsaro, 1997; James \& Prout, 1997; Waller, 2006). Previous research on environmental awareness and on the preferences of school age children have shown that when students start primary school they have already developed an awareness of their environment (Cohen \& Trostle, 1990; Waller, 2006), and that students could potentially modify their environment if school management encourages them to do so (Bernardi \& Kowaltowski, 2006). Students' reports and behavior patterns here indicate that they are 
aware of their environments and that they make spatial choices accordingly, as it has also been suggested by others (Catling, 2005; Kytta et al., 2004; Thomson, 2005).

Our activity observation results show some instances in which students' space occupancy indicates some transformation in the intended use of particular spaces by students, which could be interpreted as active involvement of students in occupying their environment. In each of the three schools, we observed examples of indoor places that seem to be preferred by students, whose functions seemed to be converted according to students' needs. An example to those transformations is the use of emergency stairs in School 2. Students want private, tranquil spaces to spend time with a friend, and they want such spaces to have a view of other nonclassroom areas. When there are no such spaces, students convert the function of an alternative space into a private space such as the restrooms, especially by boys, and the emergency stairs in School 2 (Fig. 11). Students were observed at the emergency stairs talking and watching people below in the garden. The use of these emergency stairs is particularly interesting because it is frequently used by students as a secluded place which offers an excellent view to the outside, even though it is not designed for this purpose.

Another instance to those transformations is that a student (sixth grader boy) from School 1, in response to a question about his favorite place, writes that he likes most "The amphitheater: because it is a great place to play soccer. The restrooms: it is a great place for boys to chat".

According to observations and questionnaires, 'talking to each other' is one of the most frequent activities among students in the three schools. This activity requires relatively quiet places out of sight of others. In all three schools students mentioned such places inside the school building or outdoors. For example, in School 2 where the student population is relatively high and the indoor recess activity is dominant, the garden, particularly the green area, provides such tranquil sub-spaces for private talks (Fig. 12). A sixth grade, girl student from School 2 mentions this spot as her favorite place. She writes "...the benches in the garden because there is greenery around the benches. I can talk without any disturbances". Similarly, a sixth grade, boy student from School 1 writes that "one of my most favorite spots in the school is the olive grove. That place is like a forest. It has undesirable aspects. That is to say there are lot of bugs and some snakes there. But it is also rarely used. I can use this place with few of my friends to be alone. I like this place because it is quiet." A quote from a fifth grade, boy student attending School 3 is even more revealing about the use of their

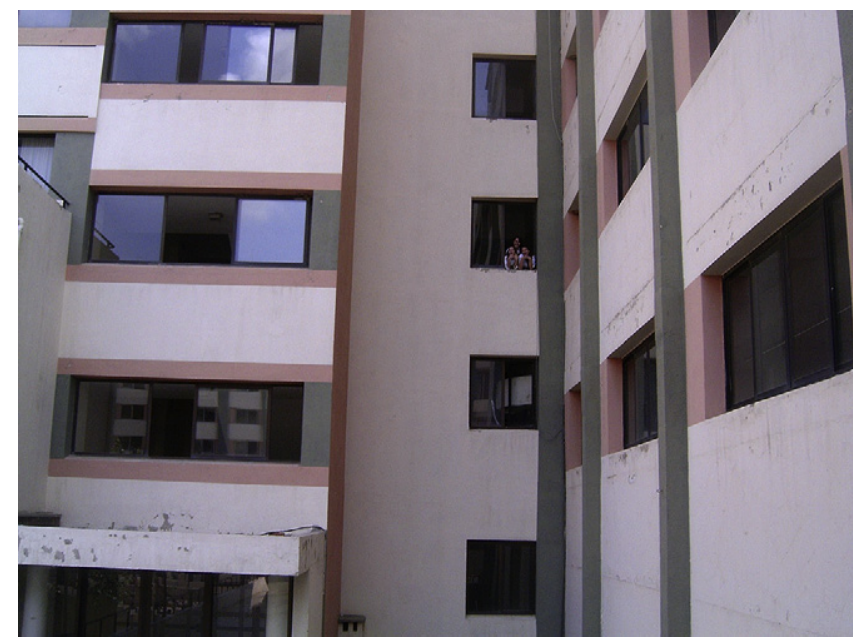

Fig. 11. Students spending time by the window of an emergency stair in Building A of School 2.

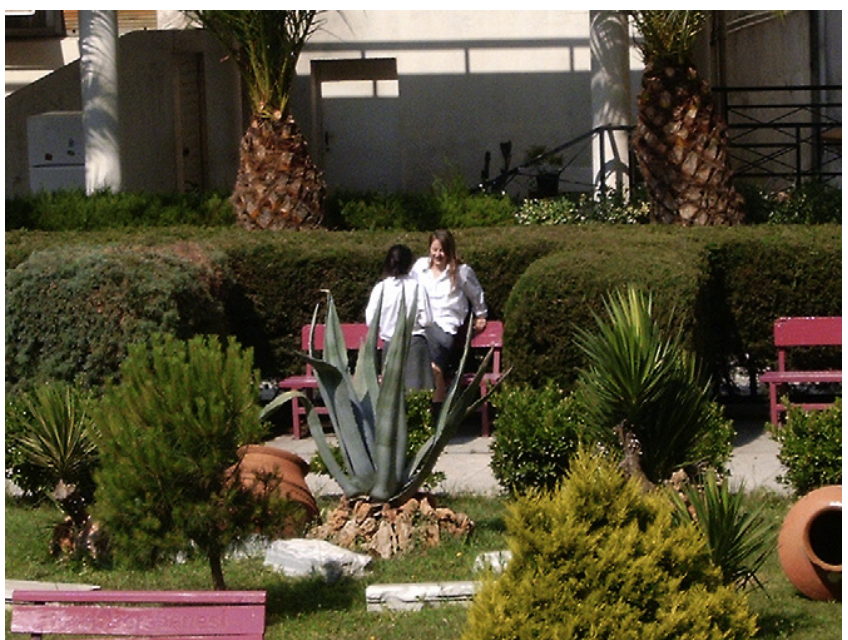

Fig. 12. One of the green niches in the garden of School 2. (For interpretation of the references to colour in this figure legend, the reader is referred to the web version of this article.).

schoolyard as both a gathering place and a private place. He writes that "I like the schoolyard. Because I can stay alone there if I want to, but I can play with my friends there also." In the schoolyard of School 3, we also observed some students using architectural elements, such as columns, to create a private space to stay alone (Fig. 13)

In School 1, the seats along the corridor of the elementary school building (Fig. 14) are one of the few examples of nonclassroom indoor places preferred by students. Since, even on rainy days, the majority of students go outside during recess, the students who spend time in the corridor seating areas can enjoy

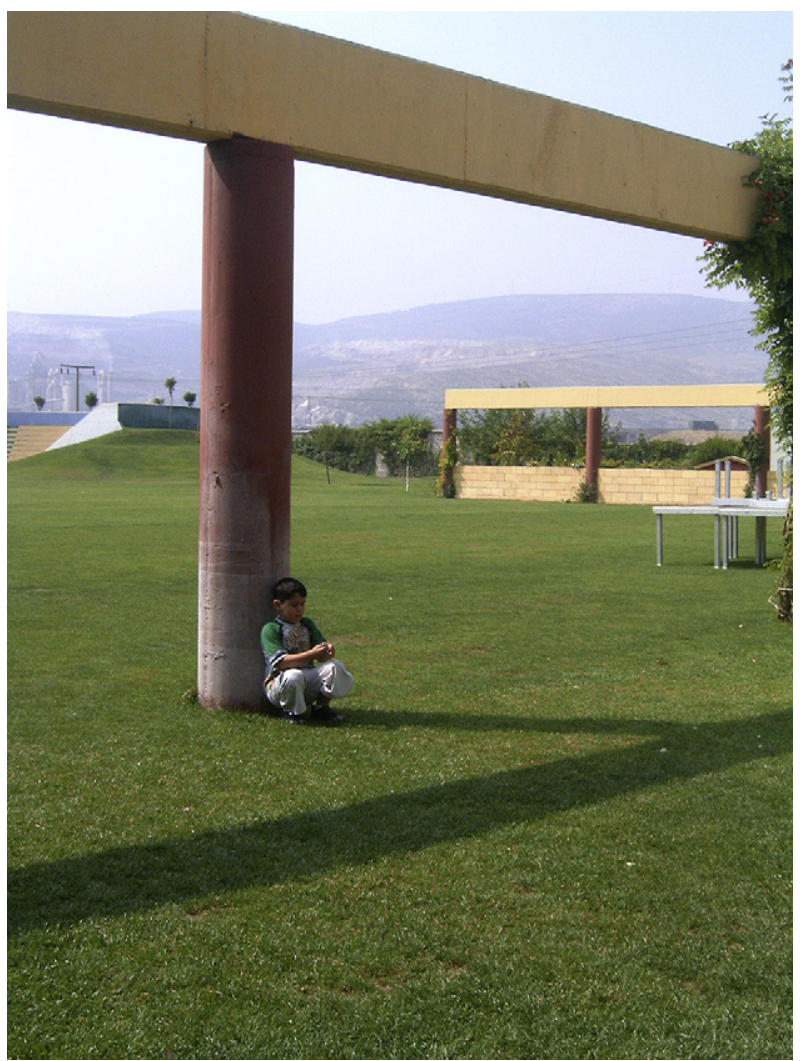

Fig. 13. A student from School 3 sitting by a column. 


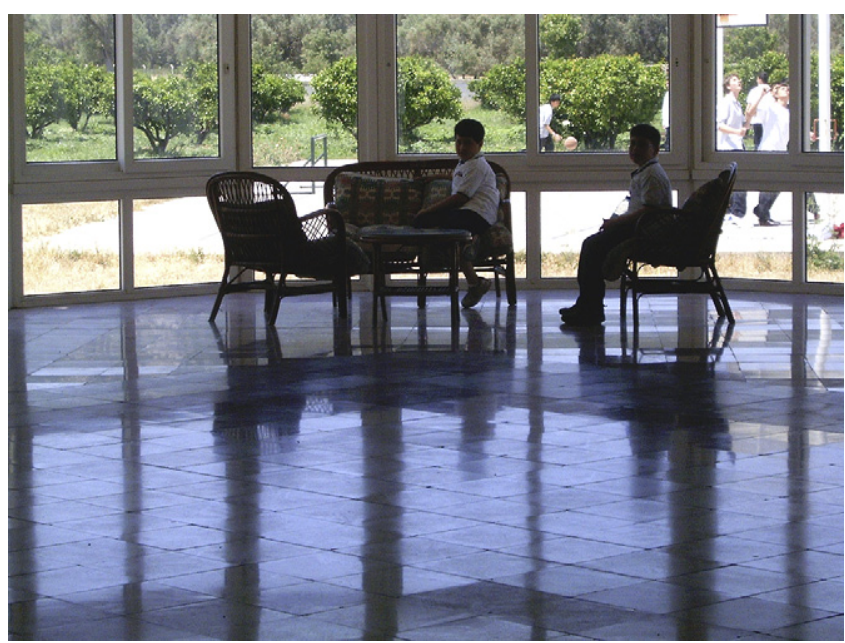

Fig. 14. The seats at the corridor of elementary school building of School 2.

more privacy when compared to crowded indoor non-classroom spaces of other schools.

Considering the number of floors and the campus layouts, the low percentage of outdoor use in School 2 can be explained by the problem of access to the garden, the lack of variety in the schoolyard, and overcrowding of the schoolyard. In contrast to School 2, all buildings of School 3 have at least 2 gates (total 13 gates) that connect indoors and outdoors and facilitate the use of the outdoor spaces.

Based on the findings, students' space preferences during recess seem to be affected by the availability of a variety of spaces (e.g., the garden of School 1, the indoor spaces of School 2 and School 3), accessibility to the outdoor space (e.g., the schoolyard of School 3), the availability of sufficient space per student (e.g., the schoolyard of Schools 1 and 3), and the spatial quality (e.g., the interior spaces of School 3). It is likely that students will tend to stay inside their classrooms or be involved in stationary activities if the school indoor and outdoor spaces lack some of the above. The results show that the lack of variety in indoor and outdoor spaces and the poor quality of space could hinder students' favorite activities. Likewise, available, high-quality spaces could support or encourage students' favorite activities. When students have an option between outdoors and indoors, they pick the option which is more conducive to their activities. If both outdoor and indoor non-classroom spaces are conducive, they tend to use both. If both have problems, more students are likely to stay inside their classrooms. Their space occupancy behaviors, reports of their favorite places and of places where they prefer to spend time altogether indicate that students are aware of their environment and make choices accordingly.

Pellegrini (1995), studying students' behaviors in different parts of a playscape, reports that different children prefer different parts of a playground and that sometimes they do prefer the same parts yet use it in different ways, according to affordances in that particular area, or that children may shape a particular area to their liking, which he claims is a sign that environment does not coerce children's behavior on the playground. Tovey (2007) suggests similarly that children convert even the most unlikely environments into play environments. Matthews and Limb (1999) claim that students play anywhere and everywhere. Clark and Uzzell (2002), using Gibson's theory of affordances, found that school environments, together with neighborhood and town centers, support social interaction and retreat behaviors among adolescents. Our results illustrate that affordances in the school environment may help students. When the environment is congested and lacks variety, or offers little affordances, students may not be able to shape the environment to their particular needs, and they might be forced to use alternative environments, such as the case for the girls in School 1, who prefer to be outside almost as much as boys, and the boys in School 2 who are inside almost as much as the girls. This result might suggest that even though there are general tendencies among boys and girls in secondary school to prefer particular spaces during recess, it might also be true that students become more flexible in their selection of environment as they get older, as suggested by Blatchford (1998a), who claims that in secondary school there seems to be a disconnect between environment and activity.

\section{Conclusion}

The results indicate that environmental differences impact students' preferences of indoor and outdoor spaces both for girls and for boys, and that this is true for students from different grades. Girls seem to be more sensitive to deficiencies in their environments and boys tend to be less critical of their environment, even when it has problems. As students get older, their level of satisfaction with their schoolyard and school building decreases. Sixth and seventh grades students go out more often than fifth grade students. However, when the outdoor spaces are not adequate almost all students of these grades equally stay inside.

Analysis of the results indicates that fifth, sixth, and seventh grade students are more likely to be stationary and stay inside their classrooms when indoor and outdoor spaces are too congested, lack variety, and are inaccessible. When there is enough outdoor and indoor non-classroom spaces, students are more likely to play different kinds of games or wander around while talking, thus be more interactive with each other and with their environments and be more physically active, which is an important factor for the obesity problem among children as suggested by Ozdemir and Yilmaz (2008).

We claim that students not only occupy space according to the affordances of the space but are also aware of the features of the spaces they occupy. In the case that some of the spatial alternatives are conducive to the students' favorite activities, they tend to prefer that particular space. If there are no spatial alternatives, students either modify available spaces to accommodate a particular function or they alter their behavior, such as preferring stationary activities or staying inside the classroom. Consequently, we propose that students may be an important source of information for designing and planning the environments they will occupy, which has also been suggested by others (Catling, 2005; Kytta et al., 2004; Thomson, 2005).

Among several environmental indicators, we based our study primarily on the size of the indoor and outdoor spaces and on the amount of variety offered by these spaces. The results suggest that both size and variety are important factors in students' preferences of outdoor and indoor spaces. The size of the spaces is important because when students feel there is congestion in an area they tend to avoid those spaces, probably those who are in a weaker position more so than others. Variety within the spaces is important because individual, gender, and age differences require sub-spaces with different affordances for different students. We realize that there are other important environmental indicators which we have not looked at. Future studies might look into the effects of other spatial factors, such as spatial configuration, natural and artificial lighting, acoustics, and visibility, on students' space preferences. Furthermore, there were limitations in conducting field observations. Lackney (1996) mentions the difficulty of conducting unobtrusive observations in schools "due to the nature of the school with dozens of eyes on the researcher" (p.104). During this study, the students were interested in the process and frequently asked questions about the research, particularly during the non- 
stationary observations. This intervention of students were not an obstacle to the observation process, but considered as an opportunity for conversations with the students (occupants) of that school to gain more definite field notes.

This study investigated the role of the physical environment and how it impacts students' choice of indoor and outdoor spaces and their activities. The venues for further researches might be as follows:

- An in-depth study investigating particular traditions about students' choices of space and activities. Armitage (2005) points out how children's games and plays survive through generations. In those instances where there are strong traditions regarding children's games and plays one would expect to see a relatively lower impact of physical environment on children's activities.

- An investigation into differences and similarities in the space preferences and activity patterns of children in public schools and private schools. Public schools in general provide less space and less variety for their students as opposed to public schools. When children are getting to be more and more marginalized in using public spaces as suggested by Tovey (2007), the importance ofopen spaces in public schools becomes even more crucial.

- A study with a focus on how randomly-selected students from schools with different indoor and outdoor spaces will differ from each other. This will require tracking individual students and recording their activities over time and space rather than a placebased behavioral mapping. Such a study could point out further individual differences among children of same age and gender. This, however, will necessitate spending more time on observation, which means more intrusion on the part of the observer.

- A more analytical investigation of the role of spatial configuration using methods such as space syntax (Hillier, 1996; Hillier \& Hanson, 1984). A future study could look at the co-presence of students in particular sub-spaces and how this relates to the spatial configuration through space syntactical analysis. Using space syntax analysis, one might also look into how the increased chance of encounters in a school facility fosters social interactions among students from different classrooms. Furthermore, one might investigate space preferences among public school students and see whether there are any significant differences between private and public school students in terms of their space preferences.

The results from our study imply that designers and planners must be more aware of students' needs and should take students as a primary source of information in the design process, as has also been suggested by Sanoff (2000a). Second, teachers and administrators should make every effort to ensure that the non-classroom spaces are easily accessible and rich in affordances for students.

\section{Acknowledgements}

We would like to thank Craig Zimring for his insightful contributions to an earlier version of this paper and the anonymous reviewers for their comments and suggestions.

\section{References}

Armitage, M. (2005). The influence of school architecture and design on the outdoor play experience within the primary school. Paedagogica Historica, 41(4), 535-553. Bernardi, N., \& Kowaltowski, D. (2006). Environmental comfort in school buildings: a case study of awareness and participation of users. Environment and Behavior, 38(2), 155.

Blatchford, P. (1998a). Social life in school: Pupils' experience of breaktime and recess from 7 to 16 years. London; Bristol, PA: Falmer Press, Taylor \& Francis Group.
Blatchford, P. (1998b). The state of play in schools. Child Psychology and Psychiatry Review, 3(02), 58-67.

Burke, C. (2005). Play in focus: children researching their own spaces and places for play. Children, Youth and Environments, 15(1), 27-53.

Catling, S. (2005). Children's personal geographies and the English primary school geography curriculum. Children's Geographies, 3, 325-344.

Clark, C., \& Uzzell, D. L. (2002). The affordances of the home, neighbourhood, school and town centre for adolescents. Journal of Environmental Psychology, 22(1-2), 95-108.

Cohen, S., \& Trostle, S. L. (1990). Young children's preferences for school-related physical-environmental setting characteristics. Environment and Behavior, 22(6), 753-766.

Collins, D., \& Coleman, T. (2008). Social geographies of education: looking within, and beyond, school boundaries. Geography Compass, 2(1), 281-299.

Corsaro, W. A. (1997). The sociology of childhood. Thousand Oaks, CA: Pine Forge Press.

Dudek, M. (2000). Architecture of schools: The new learning environments. Oxford: Architectural Press.

Durán-Narucki, V. (2008). School building condition, school attendance, and academic achievement in New York city public schools: a mediation model. Journal of Environmental Psychology, 28, 278-286.

Dyment, J. E., \& Bell, A. C. (2007). Active by design: promoting physical activity through school ground greening. Children's Geographies, 5(4), 463-477.

Evans, J. (1997). Rethinking recess: signs of change in Australian primary schools. Education Research and Perspectives, 24(1), 14-27.

Garton, A. F., \& Pratt, C. (1987). Participation and interest in leisure activities by adolescent schoolchildren. Journal of Adolescence, 10(4), 341-351.

Groning, G. (1986). An attempt to improve a school yard. Children's Environments Quarterly, 3(3), 12-19.

Hart, R. (2002). Containing children: some lessons on planning for play from New York city. Environment and Urbanization, 14(2), 135-148.

Heusser, C. P., Adelson, M., \& Ross, D. (1986). How children use their elementary school playgrounds. Children's Environments Quarterly, 3(3), 3-11.

Hillier, B. (1996). Space is the machine: A configurational theory of architecture. Cambridge/New York: Cambridge University Press.

Hillier, B., \& Hanson, J. (1984). The social logic of space. Cambridge/New York: Cambridge University Press.

James, A., \& Prout, A. (1997). Constructing and reconstructing childhood: Contemporary issues in the sociological study of childhood. London/Washington, DC: Falmer Press.

Killeen, J. P., Evans, G. W., \& Danko, S. (2003). The role of permanent student artwork in students' sense of ownership in an elementary school. Environment and Behavior, 35(2), 250-263.

Korpela, K., Kytta, M., \& Hartig, T. (2002). Restorative experience, self-regulation, and children's place preferences. Journal of Environmental Psychology, 22(4), 387-398

Kumar, R., O'Malley, P. M., \& Johnston, L. D. (2008). Association between physical environment of secondary schools and student problem behavior: a national study, 2000-2003. Environment and Behavior, 40(4), 455-486.

Kytta, M., Kaaja, M., \& Horelli, L. (2004). An internet-based design game as a mediator of children's environmental visions. Environment and Behavior, 36(1), 127-151.

Lackney, J. A. (1996). Quality in school environments: A multiple case study of the diagnosis, design and management of environmental quality in five elementary schools in the Baltimore city public schools from an action research perspective. Vols. I and II. Unpublished doctoral thesis, University of Wisconsin, Milwaukee.

Lackney, J. A. (1999). Assessing school facilities for learning/Assessing the impact of the physical environment on the educational process: Integrating theoretical issues with practical concerns. Paper presented at the UEF21 New Jersey Institute of Technology Conference, Newark, NJ.

Lewis, T. E., \& Phillipsen, L. C. (1998). Interactions on an elementary school playground: variations by age, gender, ace, group size, and playground area. Child Study Journal, 28(4), 309-320.

Lindholm, G. (1995). Schoolyards: the significance of place properties to outdoor activities in schools. Environment and Behavior, 27(3), 259-293.

Malinowski, J. C., \& Thurber, C. A. (1996). Developmental shifts in the place preferences of boys aged 8-16 years. Journal of Environmental Psychology, 16(1), 45-54.

Matthews, H., \& Limb, M. (1999). Defining an agenda for the geography of children: review and prospect. Progress in Human Geography, 23(1), 61-90.

Moore, G. T. (1986). Effects of the spatial definition of behavior settings on children's behavior: a quasi-experimental field study. Journal of Environmental Psychology, 6(3), 205-231.

Moore, R. C. (1986). The power of nature orientations of girls and boys toward biotic and abiotic play settings on a reconstructed schoolyard. Children's Environments Quarterly, 3(3), 52-69.

Ozdemir, A., \& Yilmaz, O. (2008). Assessment of outdoor school environments and physical activity in Ankara's primary schools. Journal of Environmental Psychology, 28(3), 287-300.

Pasalar, C. (2003). The effects of spatial layouts on students' interactions in middle schools: Multiple case analysis. Unpublished Doctoral dissertation, North Carolina State University, Raleigh.

Pellegrini, A. D. (1992). Preference for outdoor play during early adolescence. Journal of Adolescence, 15(3), 241-254.

Pellegrini, A. D. (1995). School recess and playground behavior: Educational and developmental roles. Albany: State University of New York Press.

Pellegrini, A. D. (2005). Recess: Its role in education and development. Mahwah, NJ: L. Erlbaum Associates. 
Pellegrini, A. D., \& Blatchford, P. (2002). Time for a break. The Psychologist, 15(2), 60-62. Pellegrini, A. D., Kato, K., Blatchford, P., \& Baines, E. (2002). A short-term longitudinal study of children's playground games across the first year of school: implications for social competence and adjustment to school. American Educational Research Journal, 39(4), 991.

Pellegrini, A. D., \& Smith, P. K. (1998). Physical activity play: the nature and function of a neglected aspect of play. Child Development 577-598.

Pinciotti, P., \& Weinstein, C. S. (1986). The effects of a tire playground on children's attitude toward play time. Children's Environments Ouarterly, 3(3), 30-39.

Sanoff, H. (2000a). Community participation methods in design and planning. New York: Wiley.

Sanoff, H. (2000b). School building assessment methods. Washington DC: National Clearing House for Educational Facilities.

Spencer, C., \& Woolley, H. (2000). Children and the city: a summary of recent environmental psychology research. Child: Care, Health and Development, 26(3), 181-198.
Tanner, C. K. (2000). The influence of school architecture on academic achievement Journal of Educational Administration, 38(4), 309-330.

Thomson, S. (2005). "Territorialising" the primary school playground: deconstructing the geography of playtime. Children's Geographies, 3(1), 63-78.

Thurber, C. A., \& Malinowski, J. C. (1999). Environmental correlates of negative emotions in children. Environment and Behavior, 31(4), 487-513.

Titman, W. (1994). Special places; special people: The hidden curriculum of school grounds. Godalming: World Wide Fund for Nature.

Tovey, H. (2007). Playing outdoors: Spaces and places, risk and challenge. Maidenhead: Open University Press.

Tuncer, G., Ertepinar, H., Tekkaya, C., \& Sungur, S. (2005). Environmental attitudes of young people in Turkey: effects of school type and gender. Environmental Education Research, 11(2), 215-233.

Waller, T. (2006). Don't come too close to my octopus tree': recording and evaluating young children's perspectives on outdoor learning. Children, Youth and Environments, 16(2), 75-104. 